\title{
The Effect of Ginger Herbal Drink on Hyperemesis Gravidarum in the First Trimester Pregnant Women
}

\author{
Siska Nurul Abidah ${ }^{1 *(\mathbb{D})}$, Fritria Dwi Anggraini ${ }^{1}$ (D) Fauziyatun Nisa ${ }^{\prime 1}$ (D) Siti Nur Hasina ${ }^{2}$ (D) \\ ${ }^{1}$ Department of Midwifery, Faculty of Nursing and Midwifery, Universitas Nahdlatul Ulama Surabaya, Surabaya, East Java, \\ Indonesia; ${ }^{2}$ Department of Nursing, Faculty of Nursing and Midwifery, Universitas Nahdlatul Ulama Surabaya, Surabaya, East \\ Java, Indonesia
}

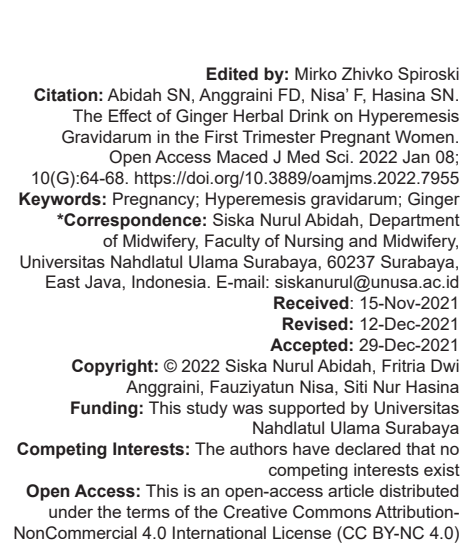

\section{Introduction}

Nausea and vomiting an initial complaint in pregnancy was experienced by most women, if excessive impact on the health of the mother and fetus in the content. The percentage incidence of hyperemesis gravidarum in Indonesia ranges from $1 \%$ to $3 \%$ of all pregnancies. Nausea and vomiting that occur in pregnancy are caused by increased levels of the hormones estrogen and progesterone produced by human chorionic gonadotropin (HCG) in the serum in the placenta. Nausea and vomiting occur in $60-80 \%$ of primigravida and $40-60 \%$ in multigravida [1]. Nausea and vomiting experienced by pregnant women more than 5 times a day can harm pregnant women and their fetuses because pregnant women need balanced and adequate nutrition. Psychologically, nausea and vomiting or emesis gravidarum (nausea in the morning) during pregnancy affects $80 \%$ of pregnant women, and has a significant effect on quality of life. Most pregnant women consider nausea and vomiting as a normal thing during pregnancy, some feel it as something that is uncomfortable and can interfere with daily activities [2].

In general, pregnant women who experience nausea and vomiting feel uncomfortable and want to end this period. Therapy to reduce nausea and vomiting in the medical world is known as two therapies, namely pharmacological therapy and non-pharmacological therapy. The side effects of pharmacological drugs if used freely and repeatedly without a doctor's supervision can pose a risk that endangers the body, as an alternative, various studies are carried out to find replacement therapy or complementary therapies that are safer when compared to pharmacological therapy, namely using non-pharmacological therapies such as types of medicinal plants. Ginger is often used.

Ginger is a rhizome plant with the Latin name Zingiber officinale which belongs to the Zingiberaceae family. The chemical constituents of ginger are shogaols, gingerols, bisapolene, zingiberene, zingiberol, 
sesquiphellandrene, essential oils, and resins. Ginger contains flying oil (essential oil) which is refreshing and blocks the gag reflex, while gingerols and shogaols can improve blood circulation and nerves work well and have anti-nausea, anti-vomiting, analgesic, sedative, antipyretic, and anti-bacterial effects [3]. One of the pharmacological functions of ginger is antiemetic (antivomiting) which is an ingredient that is able to expel gas in the stomach which will control vomiting by increasing intestinal peristaltic movements. About 6 compounds in ginger have been shown to be effective antiemetics. These compounds are more directed at the stomach wall than the central nervous system. Ginger is usually safe as herbal medicine; ginger does not have acute toxicity at doses commonly consumed for food or medicine [4].

This is supported by research conducted by Tiran (2012) analyzing ginger to reduce nausea and vomiting during pregnancy and the study found that ginger can reduce nausea and vomiting during pregnancy [5]. This is supported by Ding et al. (2013) analyzing the effectiveness and safety of ginger for nausea and vomiting in pregnancy and the study found that ginger can be used as a safe and effective treatment for pregnant women who experience nausea and vomiting [6]. In addition, according to Kalava et al. (2013) analyzed the efficacy of ginger on nausea and vomiting given to intra- and post-operative patients and the study found that ginger can reduce intraoperative nausea compared to placebo [7]. The study of Sharifzadeh et al. (2018) analyzed the comparison of ginger, placebo and vitamin B6 to reduce nausea and vomiting and the study found that ginger was more effective than placebo for the treatment of nausea and vomiting and comparable to vitamin B6 [8]. In addition, Lete and Allue (2016) analyzed the effectiveness of ginger in preventing nausea and vomiting during pregnancy and the study found that ginger is an effective and safe treatment for nausea and vomiting during pregnancy and nausea and vomiting due to medication [9].

Ginger is an herbal plant that has long been known to prevent nausea and vomiting, but people do not know more about the benefits of ginger for pregnant women. Therefore, the purpose of this study was to analyze the effect of giving ginger herbal drink in reducing the level of hyperemesis gravidarum in first trimester pregnant women.

\section{Method}

\section{Research background}

This study was conducted in July 2021. This study was conducted on pregnant women in the Gresik area. In this study, they were divided into two groups consisting of 48 in the experimental group given ginger herbal drink and 48 in the control group given water and sugar to determine whether or not ginger drink was effective in reducing the frequency of hyperemesis gravidarum.

\section{The procedure for collecting data}

This research design used a quasiexperimental with control group with a pre- and post-test approach. Samples were taken using the consecutive sampling technique by determining the inclusion criteria: experiencing nausea and vomiting more than 2 times a day and not taking anti-nausea vomiting drugs, being not suffering from other diseases and willing to be respondents. Exclusion criteria from the study were experiencing shortness of breath, bleeding and not willing to be a respondent. The data collection method used in this study refers to Yanuaringsih et al. (2020) with slight modifications. In brief, the stages of data collection are as follows. The treatment group was given ginger herbal drink, and the control group was given water and sugar. The independent variable in this study was ginger herbal drink. The type of ginger used is emprit ginger obtained from the traditional market as much as $2.5 \mathrm{~g}$, sliced and brewed with $250 \mathrm{ml}$ of hot mineral water plus 1 tablespoon of sugar $(10 \mathrm{~g})$ taken $2 \times 1$ a day for 7 days [10]. The dependent variable is a decrease in the frequency of hyperemesis gravidarum, namely the number of times a day the frequency of emesis gravidarum experienced by pregnant women. Measurements used a pregnancy unique quantification of emesis and nausea (PUQE-24) questionnaire to measure the severity of nausea and vomiting in $24 \mathrm{~h}$. The PUQE score for each patient was calculated using three criteria to assess the severity of nausea and vomiting during pregnancy (number of hours of feeling nauseated, number of episodes of vomiting, and number of episodes of dry vomiting in the last $24 \mathrm{~h}$ ). The PUQE score was calculated by adding the values of each criterion, namely 3 (no vomiting), 4-7 (mild), 8-11 (moderate) and 12-15 (severe) [1] The PUQE score was measured before being given treatment in the form of giving ginger water to the intervention group, while the control group was not given treatment but the PUQE score was measured together with the intervention group in the form of pretest and the development of the level of emesis which was measured every day for 7 days and the results from the past day were used as results in this study.

\section{Methods/procedures of data analysis}

The analysis used in this study was to determine the difference in the effectiveness of reducing the frequency of hyperemesis gravidarum before and after intervention in the experimental group and the control 
group using the Wilcoxon rank test. Before intervention, the experimental group and the control group used the test Mann-Whitney. After the intervention was carried out in the experimental and control groups using the test Mann-Whitney. Moreover, the difference in the decrease in the frequency of hyperemesis gravidarum in the experimental and control groups using the test Mann-Whitney. Data were analyzed using SPSS 23 with coding for hyperemesis level 1 (severe hyperemesis), 2 (moderate hyperemesis), 3 (mild hyperemesis), and 4 (no hyperemesis).

\section{Research ethics}

Ethical clearance has been issued by the ethics institute of Universitas Nahdlatul Ulama Surabaya under Number 078/EC/KEPK/UNUSA/2021.

\section{Results}

Table 1 shows that the characteristics respondents in this study according to maternal age; the results showed that most $(77.08 \%)$ of respondents in the intervention group were at the age of 20-35 years, while in the control group most (75\%) were in the age of 20-35 years. Characteristics according to parity in the intervention group were mostly $(54.17 \%)$ primigravida. while in the control group most (58.33\%) were primigravida. Characteristics according to gestational age in the intervention group mostly $(52.08 \%)$ ranged from 1 to 4 weeks of gestation, while in the control group most $(47.92 \%)$ the gestational age range is also 1 to 4 weeks.

Table 1: Characteristics of Respondents by Maternal Age, Parity and Gestational Age in the Control Group and the Experimental Group

\begin{tabular}{|c|c|c|c|c|}
\hline \multirow[t]{3}{*}{ Category } & \multicolumn{4}{|c|}{ Group } \\
\hline & \multicolumn{2}{|c|}{$\begin{array}{l}\text { Intervention } \\
(\mathrm{n}=48)\end{array}$} & \multicolumn{2}{|c|}{$\begin{array}{l}\text { Control } \\
(n=48)\end{array}$} \\
\hline & $\mathrm{n}$ & $\%$ & $\mathrm{n}$ & $\%$ \\
\hline \multicolumn{5}{|l|}{ Maternal age } \\
\hline$>20$ years & 5 & 10.42 & 3 & 6.25 \\
\hline $20-35$ years & 37 & 77.08 & 36 & 75 \\
\hline$>35$ years & 6 & 12.5 & 9 & 18.75 \\
\hline \multicolumn{5}{|l|}{ Parity } \\
\hline Primigravida & 26 & 54.17 & 28 & 58.33 \\
\hline Multigravida & 19 & 39.58 & 17 & 35.42 \\
\hline Grandemultigravida & 3 & 6.25 & 3 & 6.25 \\
\hline \multicolumn{5}{|l|}{ Gestational Age } \\
\hline 1-4 weeks & 25 & 52.08 & 23 & 47.92 \\
\hline 5-8 weeks & 20 & 41.67 & 22 & 45.83 \\
\hline $9-12$ weeks & 3 & 6.25 & 3 & 6.25 \\
\hline
\end{tabular}

Table 2 shows that the average frequency level of hyperemesis gravidarum in the intervention group was 2.2083 and 2.2292 in the control group. The results of the analysis using the Mann-Whitney Test obtained a value with $p=0.806$ meaning that there was no difference in the average frequency level of hyperemesis gravidarum in the intervention group and
Table 2: Frequency of hyperemesis gravidarum in the intervention group and control group before being given the intervention $(n=48 ; n=48)$

\begin{tabular}{llllll}
\hline Group & Mean & SD & Min & Max & p value \\
\hline Intervention & 2.2083 & 0.425 & 2 & 3 & 0.806 \\
Control & 2.2292 & 0.410 & 2 & 3 & \\
\hline
\end{tabular}

the control group before intervention.

Table 3 shows that the average frequency level of hyperemesis gravidarum in the intervention group was 3.4375 and 2.2917 in the control group. The results of the analysis using the Mann-Whitney Test obtained a value with $p=0.000$ meaning that there is a difference in the average frequency level of hyperemesis gravidarum in the intervention group and the control group after being given the intervention.

Table 3: Frequency of hyperemesis gravidarum in the intervention group and control group after being given the intervention $(n=48 ; n=48)$

\begin{tabular}{llllll}
\hline Group & Mean & SD & Min & Max & p value \\
\hline Intervention & 3.4375 & 0.425 & 2 & 3 & 0.000 \\
Control & 2.2917 & 0.503 & 1 & 4 & \\
\hline
\end{tabular}

Based on Table 4, the results of the Wilcoxon test statistical test obtained $p=0.000$ in the intervention group and obtained $p=0.157$ in the control group, $p<0.05$ it can be concluded that there is a significant decrease in the frequency level of hyperemesis gravidarum before and after being given ginger herbal drink intervention group and the control group. So that giving ginger herbal drink can reduce the frequency of hyperemesis gravidarum.

Table 4: Frequency of hyperemesis gravidarum level (pre- and post-test ) in the intervention group and the control group ( $n=48 ; n=48$ )

\begin{tabular}{llll}
\hline Group & Mean & SD & p value \\
\hline Intervention & & & \\
Pre & 2.2292 & 0.425 & 0.000 \\
Post & 3.4375 & 0.580 & \\
Control & & & \\
Pre & 2.2083 & 0.410 & 0.157 \\
Post & 2.2917 & 0.503 & \\
\hline
\end{tabular}

\section{Discussion}

Hyperemesis gravidarum is caused because during pregnancy there will be hormonal changes so that complaints in first trimester pregnant women are usually nausea and vomiting. The hormone that affects nausea and vomiting is HCG (Chorionic Gonadotropin Hormone). In this study, it was found that the majority of mothers were at the age of 20-35 years, and the majority were primigravida where according to research conducted by emami (2018) said that hyperemesis gravidarum was more often experienced by primigravida than multigravida. This is related to the level of stress and the mother's age at the time of her first pregnancy. Primigravida mothers have not been able to adapt to the hormones estrogen and chorionic gonadotrophin. 
The increase in this hormone makes gastric acid levels increase, causing complaints of nausea. In this study, the majority of the mother's gestational age was 1-4 weeks [11]. During early pregnancy, HCG hormone levels will increase and reach their highest levels, causing decreased digestibility and intestinal peristalsis. Gastric acid increases and decreases appetite and causes a painful effect in the stomach in the form of nausea [12].

The frequency level of hyperemesis gravidarum before the intervention was given a significance value of 0.163 , which means that there was no significant difference in the frequency of hyperemesis gravidarum between the experimental group and the control group. Meanwhile, after being given an intervention for 7 days in the experimental group and the control group, the results obtained a significance value of 0.000 which means there is a significant difference between the experimental group and the control group.

How to overcome hyperemesis gravidarum can be done by giving traditional ingredients such as ginger which can overcome nausea and vomiting by brewing. Ginger contains essential oil levels, starch content, fiber content, ash content and contains gingerol which is useful for the body which is proven to have antiemetic activity (anti-vomiting) which blocks serotonin so that during contraction of the muscles of the digestive tract it will relax and weaken so that nausea will decrease [13]. Ginger infusion overcomes nausea and vomiting in pregnant women in the first trimester, where nausea and vomiting are caused by changes in the endocrine system during pregnancy, mainly due to high fluctuations in HCG levels. Ginger contains zingerone substances and the aroma of ginger is caused by zingiberol substances. Ginger can work by blocking receptors serotonin and causing an antiemetic effect on the gastrointestinal system, thereby reducing nausea and vomiting [11].

Research conducted by Viljoen (2014) also said that ginger has pharmacological activity, namely 6 compounds that have been shown to have antiemetic effects, namely ingredients that can expel gas in the stomach so as to relieve flatulence and have strong aromatic stimulants and can control vomiting by increasing peristaltic movements in the digestive tract [14]. This is evidenced by the results of the analysis of the frequency of hyperemesis gravidarum before and after the intervention in the experimental group, the value of $=0.000$ means that there is a significant decrease in the frequency of hyperemesis gravidarum after the intervention. So that giving ginger herbal drink can reduce the frequency of hyperemesis gravidarum. Moreover, the strength of the relationship in this study is shown in the value of the average difference in the frequency levels of hyperemesis gravidarum in the experimental group and the control group, the value $=0.000$ which means that there is a significant difference in the mean frequency of hyperemesis gravidarum between the experimental group and the control group. The explanation above shows that giving ginger herbal drink can reduce the frequency of hyperemesis gravidarum.

The findings of this study are in line with the results of research by Ding et al. (2013) which showed that ginger can be used as a safe and effective treatment for pregnant women who experience nausea and vomiting [6]. This is also supported by research by Morvaridzadeh et al. (2020) which states that the results of pharmacological tests show ginger has anti-inflammatory activity; this is evidenced by mixing ginger extract in hot water to inhibit synclooxygenase and lipoxygenase activity so that prostaglandin and leukotriene levels in the blood decrease [3]. Another study conducted by Tiran (2012) said that ginger was effective and efficacious in reducing nausea and vomiting in pregnant women where pregnant women were given a supplement containing $1 \mathrm{~g}$ of ginger extract every day showing a significant decrease in nausea and vomiting symptoms [5]. Moreover, a study conducted by Sharifzadeh et al. (2018) said that ginger was more effective for nausea and vomiting compared to placebo and comparable to vitamin B6. Initial therapy for nausea and vomiting should be conservative with dietary changes, emotional support and alternative therapies such as herbs. Ginger steeping can be an alternative to overcome nausea and vomiting in pregnant women [8].

Ginger is efficacious as an antiemetic and can be used by pregnant women to reduce nausea and vomiting. Another advantage is that the price is affordable, easy to get in the market, safe and harmless because pregnant women can make it themselves. So that ginger can be used as an alternative treatment to overcome emesis gravidarum before using pharmacological antiemetic drugs.

\section{Conclusion}

Ginger herbal drinks can significantly reduce the frequency of hyperemesis gravidarum. Ginger herbal drink can be used as a safe and effective herbal medicine to reduce hyperemesis gravidarum so it is recommended for pregnant women who experience hyperemesis gravidarum to consume ginger herbal drink as a safe and effective alternative therapy to reduce hyperemesis gravidarum

\section{Acknowledgments}

The research team would like to thank all participants in this study and thank the Universitas Nahdlatul Ulama Surabaya for supporting this research. 


\section{References}

1. Lee NM, Saha S. Nausea and vomiting of pregnancy. Gastroenterol Clin North Am. 2011;40(2):309-34. https://doi. org/10.1016/j.gtc.2011.03.009

2. Soa UO, Amelia R, Octaviani DA. Comparasion of the effectiveness of giving boiled red ginger and mint leaves with lime and honey on nausea and vomiting in first trimester pregnant women at waepana Health center. Midwifery J. 2018;8(2):157. https://doi.org/10.31983/jkb.v8i2.3745

3. Morvaridzadeh $M$, Fazelian S, Agah S, Khazdouz M, Rahimlou M, Agh F, et al. Effect of ginger (Zingiber officinale) on inflammatory markers: A systematic review and meta-analysis of randomized controlled trials. Cytokine. 2020;135:155224. https://doi.org/10.1016/j.cyto.2020.155224

PMid:32763761

4. Palatty PL, Haniadka R, Valder B, Arora R, Baliga MS. Ginger in the prevention of nausea and vomiting: A review. Crit Rev Food Sci Nutr. 2013;53(7):659-69. https://doi.org/10.1080/10408398. 2011.553751 PMid:23638927

5. Tiran D. Ginger to reduce nausea and vomiting during pregnancy: Evidence of effectiveness is not the same as proof of safety. Complement Ther Clin Pract. 2012;18(1):22-5. https:// doi.org/10.1016/j.ctcp.2011.08.007

PMid:22196569

6. Ding $M$, Leach $M$, Bradley $H$. The effectiveness and safety of ginger for pregnancy-induced nausea and vomiting: A systematic review. Women Birth. 2013;26(1):e26-30. https:// doi.org/10.1016/j.wombi.2012.08.001 PMid:22951628

7. Kalava A, Darji SJ, Kalstein A, Yarmush JM, Schianodicola J, Weinberg J. Efficacy of ginger on intraoperative and postoperative nausea and vomiting in elective cesarean section patients. Eur J Obstet Gynecol Reprod Biol. 2013;169(2):184-8. https://doi.org/10.1016/j.ejogrb.2013.02.014

PMid:23510951
8. Sharifzadeh F, Kashanian M, Koohpayehzadeh J, Rezaian F, Sheikhansari N, Eshraghi N. A comparison between the effects of ginger, pyridoxine (Vitamin B6) and placebo for the treatment of the first trimester nausea and vomiting of pregnancy (NVP) J Matern Neonatal Med. 2018;31(19):2509-14. https://doi. org/10.1080/14767058.2017.1344965

PMid:28629250

9. Lete I, Allué J. The effectiveness of ginger in the prevention of nausea and vomiting during pregnancy and chemotherapy. Integr Med Insights. 2016;11:11-7. https://doi.org/10.4137/IMI. S36273

PMid:27053918

10. Yanuaringsih GP, Nasution AS, Aminah S. The effect of steeping ginger as an anti-vomiting in pregnant women in the first trimester. Window Health J. 2020;3(2):151-8. https://doi. org/10.33368/woh.v0i0.317

11. Emami-Sahebi A, Elyasi F, Yazdani-Charati J, Shahhosseini Z. Psychological interventions for nausea and vomiting of pregnancy: A systematic review. Taiwan J Obstet Gynecol. 2018;57(5):644-9. https://doi.org/10.1016/j.tjog.2018.08.005 PMid:30342643

12. Body C, Christie JA. Gastrointestinal diseases in pregnancy: Nausea, vomiting, hyperemesis gravidarum, gastroesophageal reflux disease, constipation, and diarrhea. Gastroenterol Clin North Am. 2016;45(2):267-83. https://doi.org/10.1016/j. gtc.2016.02.005 PMid:27261898

13. Alsherbiny MA, Abd-Elsalam WH, El Badawy SA, Taher E, Fares M, Torres A, et al. Ameliorative and protective effects of ginger and its main constituents against natural, chemical and radiation-induced toxicities: A comprehensive review. Food Chem Toxicol. 2019;123:72-97. https://doi.org/10.1016/j. fct.2018.10.048

PMid:30352300

14. Viljoen E, Visser J, Koen N, Musekiwa A. A systematic review and meta-analysis of the effect and safety of ginger in the treatment of pregnancy-associated nausea and vomiting. Nutr J. 2014;13(1):1-14. https://doi.org/10.1186/1475-2891-13-20 PMid:24642205 